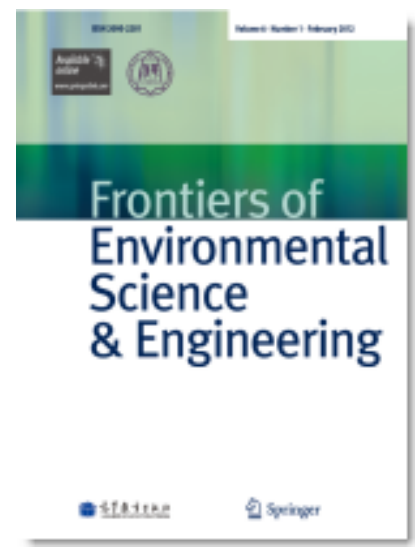

\title{
Real drive cycles analysis by ordered power methodology applied in fuel consumption, CO2, NOx and PM emissions estimation
}

\begin{tabular}{|r|l|}
\hline Journal: & Frontiers of Environmental Science and Engineering \\
\hline Manuscript ID & FESE-2020-0070.R2 \\
\hline Manuscript Type: & Original Article \\
\hline Author: & 15-May-2020 \\
\hline Complete List of Authors: & $\begin{array}{l}\text { Masclans-Abelló, Pol; Universitat Politecnica de Catalunya, CREMIT } \\
\text { Medina-Iglesias, Vicente; Universitat Politecnica de Catalunya, CREMIT } \\
\text { Santos-López, M. Antonia; Universitat Politecnica de Catalunya, CREMIT } \\
\text { Alvarez-Florez, Jesus; Universitat Politecnica de Catalunya, }\end{array}$ \\
\hline Keywords: & $\begin{array}{l}\text { Cycle Analysis by Ordered Power (CAbOP), Micro and macro models, } \\
\text { Real drive cycle, NOx/PM10/CO2 emissions, Wheel mechanical power } \\
\text { domain, Worldwide Harmonized Light-Duty Vehicles Test Cycle (WLTC) }\end{array}$ \\
\hline Speciality: & $\begin{array}{l}\text { Vehicular emissions < AIR STUDIES, Engineered systems < } \\
\text { ENVIRONMENTAL MODELING, Green engineering < SUSTAINABILITY, Air } \\
\text { pollution control / technology < OTHER RELATED AREAS }\end{array}$ \\
\hline
\end{tabular}

\section{SCHOLARONE ${ }^{\text {M }}$ Manuscripts}




\title{
Real drive cycles analysis by ordered power methodology applied to fuel consumption, $\mathrm{CO}_{2}, \mathrm{NO}_{\mathrm{x}}$ and $\mathrm{PM}$ emissions estimation
}

\author{
Running title: CAbOP applied to fuel consumption, $\mathrm{CO}_{2}, \mathrm{NO}_{\mathrm{x}}$ and $\mathrm{PM}$ emissions analysis \\ Pol Masclans Abelló1, Vicente Medina Iglesias ${ }^{1,2}$, M. Antonia de los Santos López ${ }^{1,3}$, Jesús Álvarez- \\ Flórez ${ }^{1,2, *}$
}

1.- Center for Engines and Heat Installation Research (CREMIT-UPC). Universitat Politècnica de Catalunya - BarcelonaTech. Av. Diagonal 547 (ETSEIB) 08028 Barcelona, Spain.

2.- Department of Thermal Machinery of Universitat Politècnica de Catalunya - BarcelonaTech and CREMIT -UPC.

3.- Department of Mechanical Engineering of Universitat Politècnica de Catalunya - BarcelonaTech and CREMIT -UPC.

*.- Corresponding author (e-mail: jalvarez@mmt.upc.edu).

Highlights:

- New method named CAbOP is presented based on ordering data according to power.

- Three emission models are used and their emission results compared.

- Emissions data are analysed in real driving cycles under CAbOP criteria.

- Methodology to collect data and reconstruct lost data in real urban driving cycles.

Graphical abstract

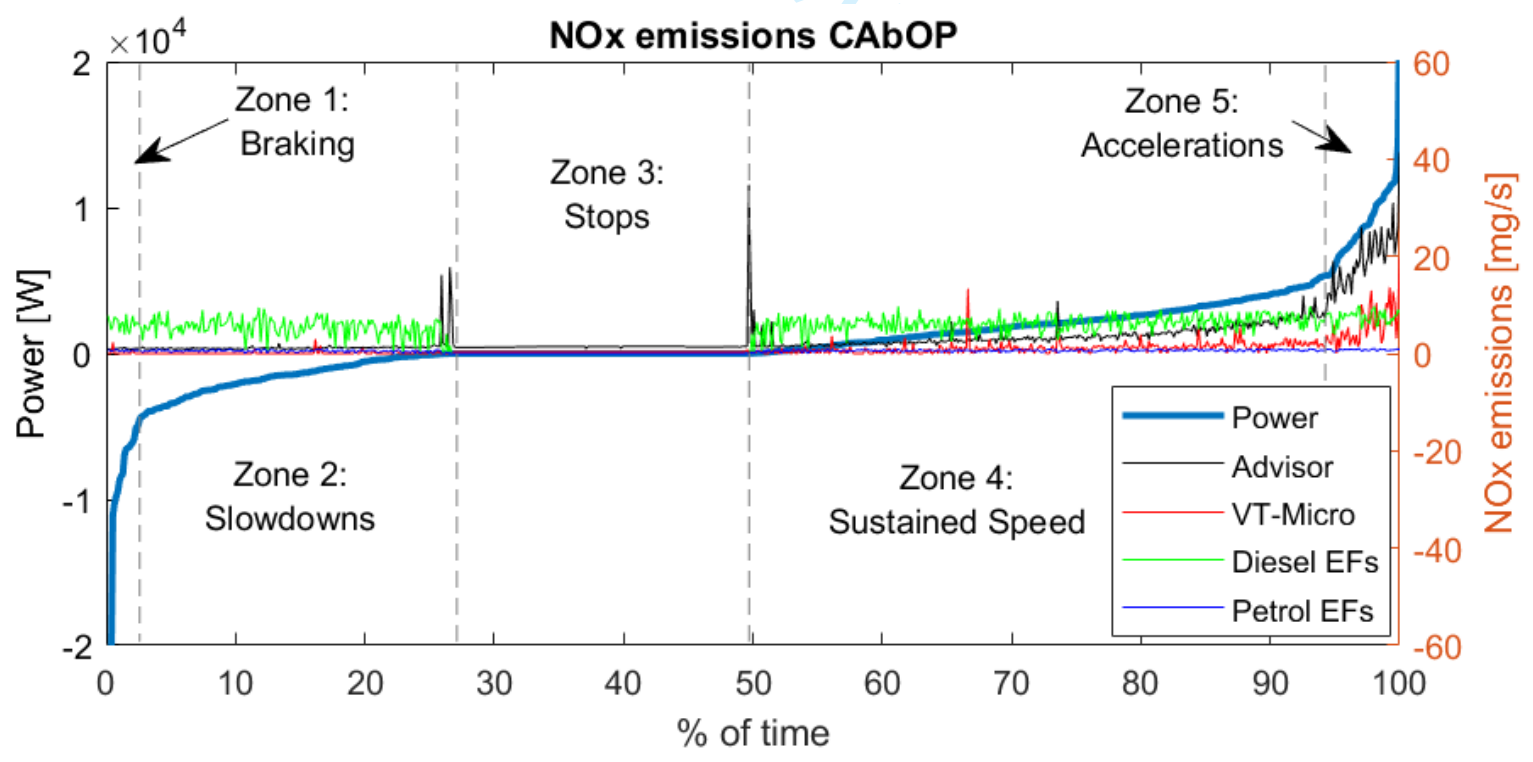

Abstract - In this work three fuel consumption and exhaust emission models, ADVISOR, VTMICRO and the European Environmental Agency Emission factors, have been used to obtain fuel consumption (FC) and exhaust emissions. These models have been used at micro-scale, using the two signal treatment methods presented. The manuscript presents: 1) a methodology to collect data 
in real urban driving cycles, 2) an estimation of FC and tailpipe emissions using some available models in literature, and 3) a novel analysis of the results based on delivered wheel power. The results include Fuel Consumption (FC), $\mathrm{CO}_{2}, \mathrm{NO}_{x}$ and $\mathrm{PM10}$ emissions, which are derived from the three simulators. In the first part of the paper we present a new procedure for incomplete drive cycle data treatment, which is necessary for real drive cycle acquisition in high density cities. Then the models are used to obtain second by second FC and exhaust emissions. Finally, a new methodology named Cycle Analysis by Ordered Power (CAbOP) is presented and used to compare the results. This method consists in the re-ordering of time dependant data, considering the wheel mechanical power domain instead of the standard time domain. This new strategy allows the 5 situations in drive cycles to be clearly visualized: hard breaking zone, slowdowns, idle or stop zone, sustained speed zone and acceleration zone. The complete methodology is applied in two real drive cycles surveyed in Barcelona (Spain) and the results are compared with a standardized WLTC urban cycle.

Index Terms - ADvanced Vehicle SimulatOR (ADVISOR), Cycle Analysis by Ordered Power (CAbOP), Computer Program to calculate Emissions from Road Transport (COPERT), - CORe INventory AIR emissions (CORINAIR), European Environment Agency (EEA), European Monitoring and Evaluation Program (EMEP), Emission Factors (EFs), Fast Fourier Transform (FTT), Finite Impulse Response (FIR), Fuel consumption (FC), Geographic Information System (GIS), Global Positioning System (GPS), Internal Combustion Engine (ICE), National Renewable Energy Laboratory (NREL), Micro and macro models, Real drive cycle, NOx/PM10/CO2 emissions, New European Drive Cycle (NEDC), Portable Emission Measurement System (PEMS), United States Environmental Protection Agency (US EPA), Wheel mechanical power domain, Worldwide Harmonized Light-Duty Vehicles Test Cycle (WLTC), Worldwide Harmonized Light-Duty Vehicles Test Procedure (WLTP).

\section{1.- INTRODUCTION}

Air quality is decreasing in cities around the world and has become a major issue that concerns both governments and public opinion due to the severe implications it may have for human health. The problem worsens when climatic conditions do not help to disperse the emissions produced by vehicles' ICEs, the particulate emissions coming from brake systems or the manufacturing processes carried out in cities, among other sources. A satisfactory monitoring of those emissions is an important issue in addressing the problem and thereby providing public administrations with relevant information that may eventually improve governance.

The European Environment Agency, as an evolution of the European Monitoring and Evaluation Program (EMEP/EEA), produces guidelines every year aiming to create a complete emission inventory which analyzes the impact from multiple human activities, including energy production, industrial processes, agricultural activity or transport (Ntziachistros and Samaras, 2017).

Several methods can be used to monitor vehicle exhaust emissions. On a micro-scale focus two different approaches have been used: statistically-derived and physically-derived estimates. The first class corresponds to those methodologies that use emission factors (EFs) derived from several vehicles tested in multiple conditions. This means that the model is developed using massive amounts of emission and energy consumption data from real vehicles. This is the most common approach used for Macro estimates, offering the results in the global context of an entire city and throughout one long period of time, such as 
a year. By contrast, the physically-derived simulations are micro-focused. They estimate the emissions produced by a single car performing a drive cycle, considering the multiple subsystems (i.e. fuel converter, catalyzer, ...) or the instant power delivered. In this case, a complete model for the car and the emissions generation is crucial. The complexity and diversity of the vehicles, however, makes it difficult to simulate a full vehicle fleet using a physical approach.

There follows a brief summary of some statistical models:

MOBILE 6.2 is a software application program developed by the US EPA that provides estimates of emissions from highway motor vehicles. The model calculates emission rates under various conditions that can be specified by the modeler, such as ambient temperatures or average traffic speeds. This model is no longer in use, as it was replaced by MOVES. The manipulation or adaptation of the program is difficult and laborious, so its use was generally limited to the United States (United States Environmental Protection Agency 2002).

The California Air Resources Board (CARB) developed its own EMission FACtors model (EMFAC) to obtain a complete emissions inventory of the region. The software was created using considerable amounts of data and studies made in the region and it is constantly under review in order to improve its reliability; however, unless it is heavily modified, its use is limited to the state of California. In at least one place, Hong Kong, the program has been adjusted to local conditions (California Air Resources Board, 2017). The European Environmental Agency (EEA) has developed the Computer Program to calculate Emissions from Road Transport (COPERT) which is part of the EMEP/EEA air pollutant emission inventory guidebook for the calculation of air pollutant emissions (Ntziachristos 2009). It is widely used by European countries to create their emissions inventories and the software contains large amounts of data, which allow for transparent and standardized calculations in accordance with EU legislation. COPERT4 is the latest version of the software, while the model is also accurately presented and distributed in the air pollutant inventory guidebook, formerly referred to as CORINAIR, which is also frequently updated and improved (Ntziachistros and Samaras, 2017).

In contrast to the statistical models, which are essentially macro models, the physical-based models can be both micro or macro depending on their intended use. Some of the available simulators are now presented:

As a successor to the MOBILE, US EPA developed the MOtor Vehicle Emissions Simulator, or MOVES. This new system is designed to be more flexible than the MOBILE model and to be able to effectively change scales from a very fine-scale analysis to national inventory estimation, as the MOVES model uses very fine-scale information, such as second-by-second resolution emissions and driving behavior. The new system consists of a toolbox of algorithms, data, and guidance necessary for use in all official US analyses associated with regulatory development, compliance with statutory requirements and national/regional inventory projections (United States Enviromental Protection Agency, 2015).

CMEM, the Comprehensive Modal Emissions Model, was developed at the University of California as a fine-scale emissions prediction model, aiming to give answers to microscopic situations in contrast with similar models such as MOBILE and EMFAC. Since its creation, it has inspired later models to use physical-based approaches for emissions modeling, as it simulated the different vehicle systems that produce the tailpipe emissions, using drive cycle data. Its latest version, 3.01 was introduced in 2006 and is available at a low cost (approximately \$20), (Feng A, et al., 1997; Barth, et al., 2000; Scora and Barth, 2006). More precise simulators such as VT-Micro, introduced by Hesham Rakha (Ahn, et al., 2002; Rakha, Ahn and Trani, 2003; Rakha, Ahn and Trani, 2004), enable real drive cycle estimation using an average of real vehicle data. The model is based on the vehicle's specific power and includes several vehicle types, which are representative of a US vehicle fleet, allowing second-by-second emission and 
consumption estimation. Diesel engines, however, are not modeled as they are not as popular in America as they are in Europe.

The ADvanced VehIcle SimulatOR, ADVISOR (Wipke, Cuddy and Burch, 1999; Markel, et al. 2002), developed at the National Renewable Energy Laboratory (NREL), allows simulations of completely defined and characterized vehicles performing customized drive cycles with a minimum precision of 1 Hz. The software, which has open source distribution, is built in MATLAB and is based on a block diagram model (SIMULINK) which simulates every subsystem in a vehicle. Although the original purpose was to help manufacturers to test and compare different propulsion systems, it has some valuable emissions data that allow precise second-by-second air pollutant estimates to be carried out.

\section{Table I}

\section{Comparison of different available simulators.}

\begin{tabular}{|c|c|c|c|c|c|c|c|}
\hline & Latest update & Type & Scope & Engines type & Drive cycle & $\begin{array}{l}\text { Considers } \\
\text { road grade? }\end{array}$ & $\begin{array}{l}\text { Considers } \\
\text { acceleration? }\end{array}$ \\
\hline MOBILE 6.2 & 2002 & Statistical & Macro & All & Average & No & No \\
\hline EMFAC & 2017 & Statistical & Macro & All & Average & No & No \\
\hline $\begin{array}{l}\text { COPERT } \\
\text { (EMEP/EPA) }\end{array}$ & $2016^{1}$ & Statistical & Macro $^{2}$ & All & Average & No & No \\
\hline MOVES & 2014 & Physical & Macro-Micro & All & Average-Real & Yes & Yes \\
\hline CMEM & 2006 & Physical & Micro & $\begin{array}{c}\text { Gasoline/ } \\
\text { Diesel }\end{array}$ & Average-Real & Yes & Yes \\
\hline $\begin{array}{l}\text { VT-Micro } \\
\text { (Rakha) }\end{array}$ & 2004 & Physical & Micro & Gasoline & Real & No & Yes \\
\hline Advisor & 2003 & Physical & Micro & $\begin{array}{l}\text { Various/ } \\
\text { Diesel }^{3}\end{array}$ & Real & Yes & Yes \\
\hline
\end{tabular}

${ }^{1}$ The last version of COPERT was introduced in 2014, however the newest version for the EMEP/EEA emission factor guidebook was published in 2016.

${ }^{2}$ A single vehicle simulation using average vehicle type data is possible using the EMEP/EEA guidance.

${ }^{3}$ The software supports various engine types, however there is only reliable emissions data for a few diesel engines, according to the documentation.

Given that $\mathrm{CO} 2$ emissions are directly related to fuel consumption, some researchers estimate those indicators using the vehicle specific power (VSP), achieving high levels of accuracy (H. Rakha, et al., 2011). This approach considers both the energy required to maintain a certain speed and the necessary power to accelerate, achieving good levels of accuracy, especially in non-Urban situations (Ben-Chaim, Shmerling \& Kuperman, 2013).

However, even the most accurate micro simulators are found to be inexact emission estimators when compared with the results obtained using the portable emissions measurement system (PEMS) (Silva, et al., 2006). The characteristics of the models are summarized in table I.

Since 2010, EU Regulations require manufacturers to specify homologated emissions for every vehicle on sale. This has encouraged some authors to develop a methodology for combining the certification data 
and the VSP approach to introduce a methodology that satisfactorily estimates fuel consumption and emissions (Duarte, Gonçalves and Farias, 2014). The official data, however, is highly influenced by the homologation cycle used: NEDC or WLTC (Donateo and Giovinazzi, 2017).

The problem of energy consumption and pollutant emissions is both a macro and micro scale problem. Therefore, it makes sense to have both macro and micro simulators. In each situation, however, there is a more critical pollutant. PM and NOx emissions are critical at a micro scale, especially in urban areas, as the latest research shows that low air quality in cities is responsible for several health problems (Kim, Kabir and Kabir, 2015; Perez, et al., 2009; Malik and Tauler, 2015). In this case the emissions and their negative impact occur in a clearly delimited zone. On the other hand, Fuel Consumption and $\mathrm{CO}_{2}$ emissions are a global problem, as they are responsible for the Greenhouse effect and their consequences are present worldwide.

According to the EMEP/EEA guidebook (Ntziachistros and Samaras, 2017), $\mathrm{CO}_{2}$ emissions come from three sources: the combustion of fuel, the combustion of lubricant oil and the addition of carbon-containing additives in the exhaust. The first source is obviously the main one, while the other sources have residual impact. Particularly, the combustion of lubricant in passenger vehicles produces between 0.43 to 2.13 $\mathrm{kg} / 10,000 \mathrm{~km}$, which represents $0.2 \%$ of the total $\mathrm{CO}_{2}$ emissions in a standard situation. The addition of carbon-containing additives in the exhaust, on the other hand, may represent as much as $1 \%$ of the total emissions; however, only Euro V and Euro VI are equipped with the after-treatment responsible for this. Thus, $\mathrm{CO}_{2}$ emissions are essentially related to the amount of fuel consumed and can be calculated using the equation (1).

$$
E_{\mathrm{CO}_{2}}=44.011 \times \frac{F C}{12.011+1.008 r_{\mathrm{H}: C}+16 r_{O: C}}
$$

Where $E_{\mathrm{CO}_{2}}$ and $\mathrm{FC}$ represent $\mathrm{CO}_{2}$ emissions and Fuel Consumption, respectively. The parameters $r_{\mathrm{H}: \mathrm{C}}=$ 1.86 and $r_{O: C}=0.0$ represent the most common ratios of Hydrogen to Carbon and Oxygen to Carbon for the fuel used in both Diesel and Gasoline engines. As the proportional relation existing between the fuel consumption and the $\mathrm{CO}_{2}$ emissions is beyond doubt, only fuel consumption will be discussed in this article, although the conclusions will be valid for both fuel consumption and $\mathrm{CO}_{2}$ emissions.

This paper aims to propose a new data analysis tool named Cycle Analysis by Ordered Power (CAbOP) which provides a novel perspective of the results in the power domain. To do so, a simple, economic and easily reproducible methodology is presented. It includes the obtention of real drive cycle data with slope (section 2), the estimation of fuel consumption and vehicle emissions on a micro scale using a simulation model (sections 3 and 4 ) and the analysis of the results in the power domain (section 4 part 4.3). The use of existing models in the literature does not aim to make a comparison between them, but to provide data for presenting the new Power analysis tool.

\section{DRIVE CYCLES ACQUISITION}

A complete drive cycle characterization requires instantaneous velocity and road grade data, which, in general, must be at least at $1 \mathrm{~Hz}$ of sample rate. This "second-by-second" sampling is, for instance, the one used in the WLTC official data (Tutuianu, et al., 2015).

Providing that the instantaneous acceleration can be derived from the velocity, at first it is not essential to measure it.

To collect the data, an electronic device capable of recording vehicle instant speed and position with a GPS tracker is used. For the GPS a sample rate of $1 \mathrm{~Hz}$ is required. These characteristics are found in most 
smartphones nowadays. Different alternatives can be considered, and some were developed, one based on a smart phone application and the other on Arduino. The Arduino option includes GPS/GSM/GPRS SIM 808 EVB-V3.2.2 and an inclinometer for road grade acquisition, while the cell-phone solution derives road grade by using GPS position complemented with GIS data.

\subsection{Data Analysis and treatment}

Using GPS for tracking vehicle speed can result in multiple issues, such as signal losses, poor precision at low speeds or a discontinuous sampling period. The data treatment performed fixes all the issues related to GPS imprecisions and malfunctioning in a reasonable manner; if the data quality is extremely poor, a repetition of the experiment should always be considered.

The objective is to obtain a file with the following 3 basic driving cycle datasets in the desired sampling frequency: 1) Longitudinal vehicle speed, 2) Longitudinal acceleration data and 3) Road grade.

In addition, the location data is needed for an initial data check and for a final plotting of the results using Geographic Information System (GIS). However, the longitudes and latitudes of a point, each related to a certain speed and time, are not necessarily lineal and so they are difficult to interpolate. For this reason, this dataset will be treated separately and combined using the absolute time when it is needed.

The advantage of having GPS data is the opportunity to plot the results of a real drive cycle simulation on a map using GIS. The data treatment varies its complexity depending on the output variable to plot. It should be considered that in high density cities, the GPS sensor signal can be lost under certain conditions. Some of these situations are: shadowing by high buildings, passing under a bridge, or long underground passes and tunnels.

If necessary, the signal can be totally reconstructed by using two synchronized sensor devices, GPS and accelerometer, with some of the possible methodologies: a) smoothing and/or filtering the longitudinal acceleration data signal (Savitzky and Golay, 1964; Bromba and Ziegler, 1981; Chen, et al., 2004; Luo, Ying and Bai, 2005) along the GPS loss driving section of the route, b) extracting data hiding and conversion signals (Bender, et al., 1996; Hentschel and Fettweis, 2000; Hardin and Hilbe, 2007) until the velocity signal is obtained by numerical integration from acceleration data, c) Matlab treatment and its tools (Sigmon and Davis, 2004) and, finally, to embed that velocity signal in the GPS velocity signal using d) cross-correlation analysis in time series (Haugh, 1976; Horvatic, Stanley and Podobnik, 2011).

Basically, as we have indicated above, the data treatment by signal processing tools used was:

The Savitzky-Golay filter, as a finite impulse response (FIR) based on a least-squares digital polynomial smoothing filter, applied on a sliding frame data with convolution process.

Resampling for sample rate conversion data is applied on a harmonic discrete signal using FFT transformations.

The Numeric derivative process is applied considering velocity data as a linear function; numerical differentiation is used to obtain longitudinal vehicle acceleration from GPS data when the GPS is not lost. Numerical integration to the acceleration data signal as a weighted sum of these values is used to approximate the integral and consequently obtain the velocity data when the GPS data is lost.

Cross correlation between two orthogonal data signals as a sliding inner product until the $\mathrm{k}$ value, with which the correlation value is maximal, is obtained. With this treatment the phasing between signals can be achieved; then the mixed data, the velocity from both the GPS sensor and the acceleration sensor can be obtained. 


\subsection{Drive Cycles}

Two real drive cycles ( $\mathrm{C} 1$ and $\mathrm{C} 2$ ), acquired in the streets of Barcelona, Spain, are displayed in this work, from the 16 acquired using the above explained methodology. Additionally, there is a third one corresponding to the WLTC Urban segment (Tutuianu, et al., 2015). The real drive cycles include road grade, so more accurate simulations can be made with those simulators supporting grade. The average speed of the three situations is intentionally similar, so the results can be compared. The 14 remaining cycles are shown later in aggregated form.

The recordings were made in the principal streets of Barcelona with a minimum of 4 lanes, where traffic lights are optimized to reduce stops. 5 different routes were created, and 3 different recordings were made in each of them. Additionally, an extra route was created (B), which was purely uphill in order to isolate this phenomenon. In order to illustrate some of the highlights of the procedure, only two are shown. The $\mathrm{C} 1$ cycle corresponds to a generally flat street, while $\mathrm{C} 2$ is an uphill cycle. The basic features are described in table II.

Table II

Cycles basic statistics

\begin{tabular}{|c|c|c|c|c|c|c|c|c|c|c|c|c|c|c|c|c|c|}
\hline Cycle & C1 & $\mathrm{C} 2$ & C3 & C4 & C5 & C6 & C7 & C8 & C9 & $\mathrm{C} 10$ & C11 & $\mathrm{C} 12$ & $\mathrm{C} 13$ & C14 & C15 & C16 & WLTC \\
\hline Route & $A$ & B & 7 & A & & C & & & $D$ & & & $E$ & & & $F$ & & - \\
\hline $\begin{array}{l}\text { Avg. Road } \\
\text { Grade }\end{array}$ & $0.3 \%$ & $2.0 \%$ & 0. & $3 \%$ & & $-2.6 \%$ & & & $1.8 \%$ & & & $-0.3 \%$ & & & $0.7 \%$ & & $0.0 \%$ \\
\hline Time [s] & 778 & 516 & 933 & 846 & 360 & 411 & 432 & 190 & 264 & 298 & 811 & 628 & 691 & 736 & 805 & 1176 & 589 \\
\hline $\begin{array}{l}\text { Distance } \\
{[\mathrm{m}]}\end{array}$ & 4420 & 2920 & 4410 & 4370 & 1510 & 1640 & 1540 & 1200 & 1430 & 1017 & 3990 & 4030 & 3230 & 3930 & 4030 & 4340 & 3130 \\
\hline $\begin{array}{l}\text { Avg. Speed } \\
{[\mathrm{km} / \mathrm{h}]}\end{array}$ & 20.46 & 20.3 & 17.01 & 18.58 & 15.09 & 14.38 & 12.78 & 22.68 & 19.47 & 14.17 & 17.70 & 23.10 & 16.81 & 19.22 & 18.02 & 13.29 & 19.11 \\
\hline
\end{tabular}

The vehicle specific power (VSP) has also been calculated using Advisor, considering a hypothetical small car with a total mass of $1040 \mathrm{~kg}$. The results are shown in Figure 1. The histogram shows the percentage of time that the cycle requires for each of the specified power ranges. C1 and WLTC cycles show similar performances, as most of the time (about 25\%) they require less than $2.5 \mathrm{~W} / \mathrm{kg}$. Cycle $\mathrm{C} 2$, due to the road grade, has a slightly different behavior and the first 3 ranges, including values from $0.1 \mathrm{~W} / \mathrm{kg}$ to $7.5 \mathrm{~W} / \mathrm{kg}$, are required between $12 \%$ and $18 \%$ each. Figure 1 does not show the instants where the requested power is equal or less than 0 , which represents $51.2 \%, 44.7 \%$ and $55 \%$ of the time, respectively. 


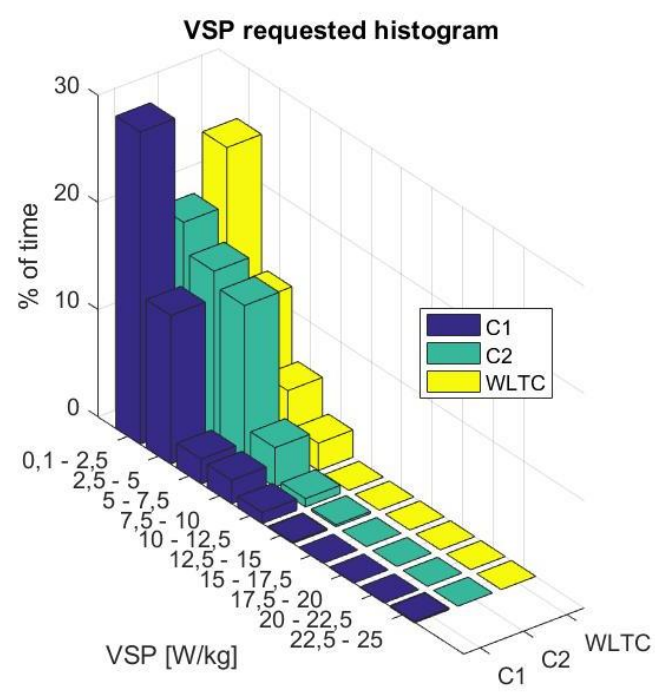

Figure 1. - Power delivered per fraction of the elapsed time.

The VSP can also be presented as a monotonously increasing function, ordering the variables by the increase in power required in the wheels. Figure 2 shows a comparison of the obtained functions in each drive cycle, in relation to the $\%$ of the cycle elapsed time. This new criterion for ordering data is the basis of the CAbOP methodology presented in this paper (Cycle Analysis by Ordered Power), in which variables such as FC or emissions are reordered according to the instant power required instead of the common temporal criterion.

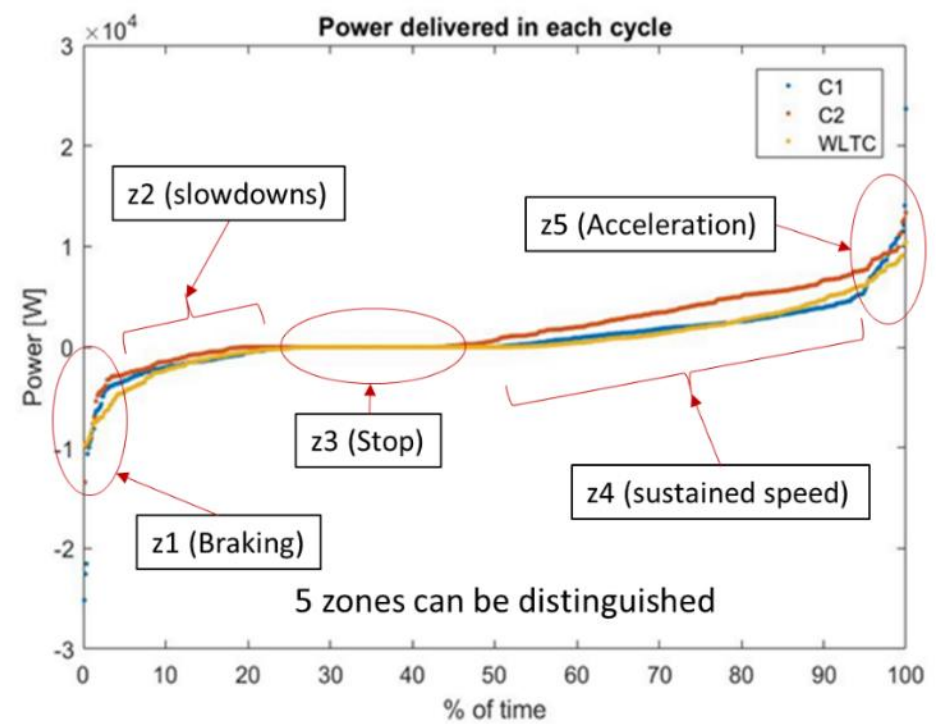

Figure 2. - Power delivered in each cycle ordered by ascending value.

The power distribution plot shown considers 4 change of tendency points which have been associated with 5 zones corresponding to different driving modes. The first zone corresponds to the hard-braking zone (braking), the second zone corresponds to driving without throttle (slowdowns), which implies a gradual loss of speed. The Idle zone corresponds to the stops performed during the cycle. The largest zone, driving 
with throttle, represents normal driving without sudden increases of speed. Finally, the accelerating zone represents the increases of speed or accelerations. Note that the cycles perform similarly in all the zones except C2 in Zone 4, which clearly requires more power than the others to keep the speed stable when going uphill.

\section{Simulation Methodology}

The present paper introduces a methodology to 1) obtain real drive cycle data, 2) estimate fuel consumption and emissions and 3) analyze the results. Figure 3 presents a model to help the reader understand this methodology.

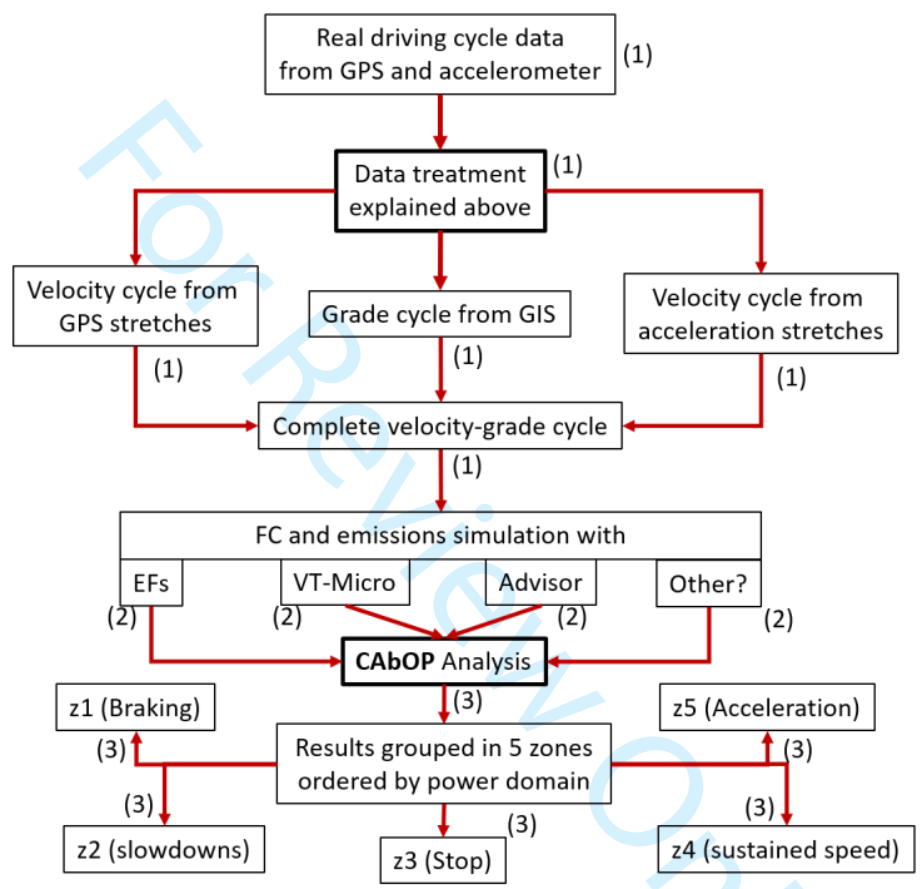

\section{Figure 3.- Model of the implemented methodology, showing the 3 different stages, as well as the multiple options offered regarding data treatment and simulation models.}

In the following section, the simulators that will be used are discussed and introduced.

From the simulators presented in the introduction, 3 have been selected for the numerical evaluation. First, the statistical and macro simulators were discarded, as the aim of the paper was to analyze emissions on a micro scale. There is, however, one exception, the EMEP/EEA EFs, which will be used for calibration. Then, from the rest of the simulators, the most easily available were Advisor and VT-Micro and, consequently, were chosen.

EEA/EMEP Guidance provides EFs for several vehicle typologies, engines and segments. Given the available data in the rest of the simulators considered, a small vehicle with either a petrol or Diesel Engine and Euro 3 homologation has been considered. The constant speed results have been obtained using equation (2), an adaptation of equation (5) in the EMEP/EEA Inventory Guidebook (Ntziachistros and Samaras, 2017) applied to our problem.

$E_{i, c}=E_{H O T: i, c}+E_{C O L D: i, c}$ 
$E_{H O T: i, c}=e_{H O T: i, c} \times l_{c}$

$E_{C O L D: i, c}=\beta_{c} \times l_{c} \times e_{H O T: i, c} \times\left(\left.\frac{e^{C O L D}}{e^{H O T}}\right|_{i}-1\right)$

Where,

$E_{i, c}$ : is the total emission or energy consumption i obtained in the cycle c

$E_{H O T: i, c}$ and $E_{C O L D: i, c}$ : are respectively the hot and cold emissions of i obtained in cycle c

$e_{H O T: i, c}$ : is the emission factor of i obtained in the cycle c. It depends exclusively on the average speed in the cycle $\mathrm{c}$

$l_{c}$ : Distance of the cycle

$\beta_{c}$ : Fraction of the cycle driven with a cold engine. Depends on $l_{c}$ and air temperature.

$\left.\frac{e^{C O L D}}{e^{H O T}}\right|_{i}$ : Cold/hot emission quotient for pollutant $\mathrm{i}$.

Apart from the usual constant speed method of calculation, operations using second by second variable speeds have also been made, considering equation (5) but using a different approach to derive $e_{\text {HOT:i,c }}$ as described in (8). This method is based on equation number nine, found in the EMEP/EEA Inventory Guidebook (Ntziachistros and Samaras, 2017), using the equation intentionally in a limited case. Here the assumption involves considering a full cycle as the sum of multiple sub-cycles of 1 second duration. Thus, emission and energy consumption rates can be derived on a second-by-second basis.

$E_{H O T: i, c}=\int\left[e_{H O T: i, c}(v(t)) \times v(t)\right] d t$

The Matlab-based ADVISOR has as its main feature a great amount of self-customization possibilities. Hence, very precise data is required when modeling a real vehicle with it, especially regarding experimental-based emission maps; it might still be difficult to obtain satisfactory results. In this case, a small vehicle chassis (named Small_car in the program) powered by a $60 \mathrm{~kW}$ Diesel engine ( $F C_{-}$CI60_emis) has been selected from the existing models in the open source version of Advisor. The available Petrol engines did not have the proper emission maps and were finally discarded, so the advisor simulations in this article correspond to Diesel vehicles.

VT-Micro uses instant power to derive consumption and emissions. It includes 5 different light duty vehicle models obtained from over 30 real vehicles. The newest vehicles, built between 1995 and 2000, are those contained in category LDV 3 and consider only Petrol engines. Then VT-Micro simulations will be used to estimate Petrol FC and emissions, considering the LDV 3 category.

\section{RESUlts}

A global comparison between Advisor and EMEP/EEA Diesel EFs is made in the following paragraphs, along with a comparison of the results using VT-Micro and Petrol EMEP/EEA Petrol. The results are presented in terms of either pollutant emissions or fuel consumption per $100 \mathrm{~km}$. As a reminder, neither the VT-Micro simulations nor the EFs consider road grade.

\subsection{Global Comparison}

Figure 4-a, 4-b and 4-c present the results for FC, NOx and PM emissions per $100 \mathrm{~km}$. The 3D charts allow the aggregated results obtained in each cycle to be compared using different models and clearly distinguishes Petrol vehicles from Diesel vehicles. 
In Figure 4-a, the FC results of Diesel second-by-second EFs agree more precisely with the Advisor results, compared with the standard constant speed EFs calculation. The trend, however, is reversed in C2 when the vehicle faces a $2 \%$ road grade. Regarding Petrol vehicles, while variances between the two different approaches for emission factor calculation are reasonably low, VT-Micro results are considerably higher, close to $47 \%$ with respect to second-by-second factors. The difference between the VT-Micro consumption results is $5.7 \%$. Finally, the Diesel estimations are lower than the Petrol ones, as one might have expected.

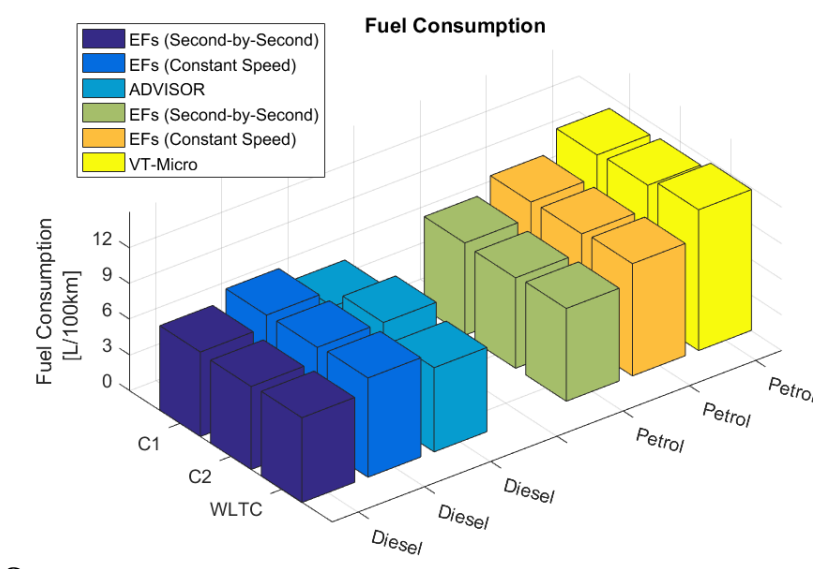

$\mathbf{a}$

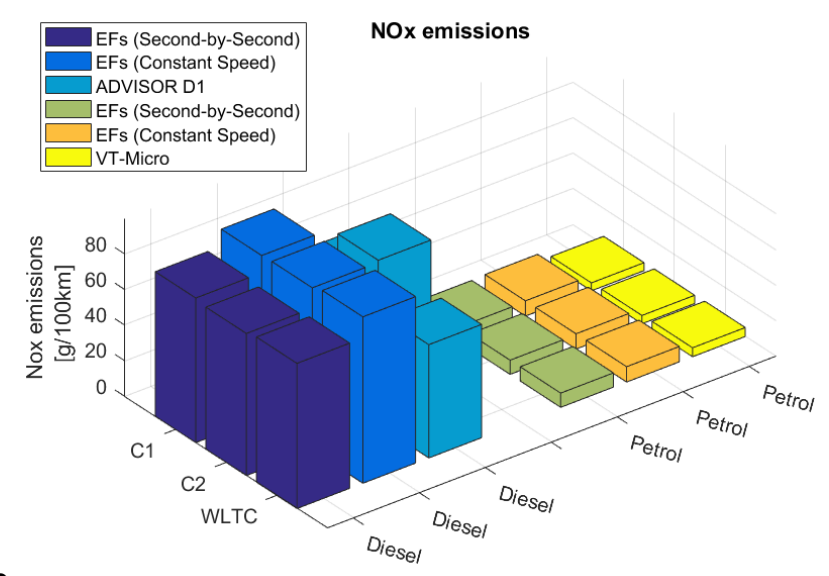

b

c

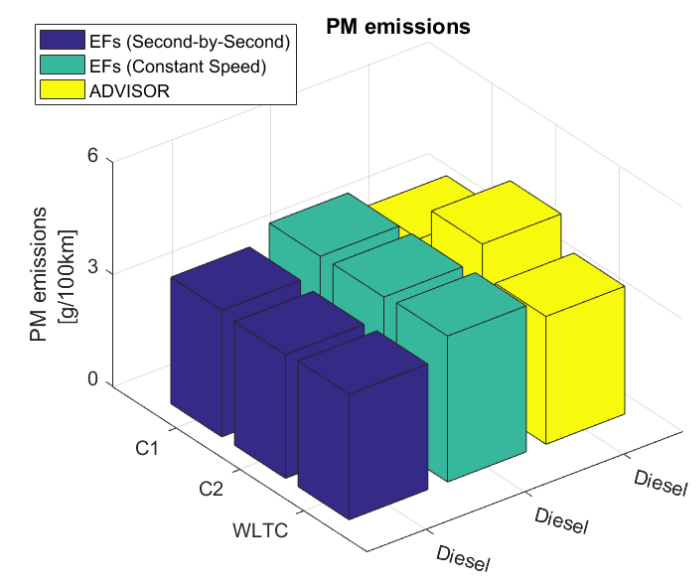

Figure 4. - (a) Estimated fuel consumption for each simulator. (b) NOx emissions in Diesel vehicles. (c) PM emissions in Diesel vehicles

The NOx emissions are presented in Figure 4-b. In each case the Diesel EFs show a greater value than the Advisor results. The effect of the road grade can also be noted in the Advisor simulations, while the EFs simulations are obviously not affected by the road grade. Emission differences between cycles using VTMicro are on average $8.7 \%$, while the comparison with EFs results shows that VT-Micro calculates $43 \%$ fewer emissions compared to the cycles. As expected, Diesel simulators show much higher emissions compared to Petrol vehicles in the same circumstances.

Figure 4-c shows that the Advisor vehicle produces a similar amount of PM to the EFs. Regarding the effect of the road grade, in both Advisor engines the C2 cycle produces between $15 \%$ to $20 \%$ more 
compared to the $\mathrm{C} 1$ and WLTC cycles. The results of PM emissions for Petrol vehicles are not shown, as VT-Micro estimates them as zero and the Petrol EFs show values almost one order of magnitude lower than the ones presented.

\subsection{Second-by-Second estimations}

The basis of satisfactory Micro simulations is their ability to estimate energy consumption and emissions on a second by second (or similar frequency) basis.

Figure 5a shows the fuel consumption and vehicle speed obtained in the $\mathrm{C} 1$ drive cycle with the different simulators. As expected, the EFs factors' consumption curve is smooth and its peaks occur at speed maximums. In contrast, VT Micro and Advisor consumption peaks relate more to acceleration. The difference between them can mostly be attributed to the higher fuel consumption of Petrol as opposed to Diesel vehicles. For this same reason, the EFs Petrol is above the EFs Diesel. Also, VT-peaks are sharper.
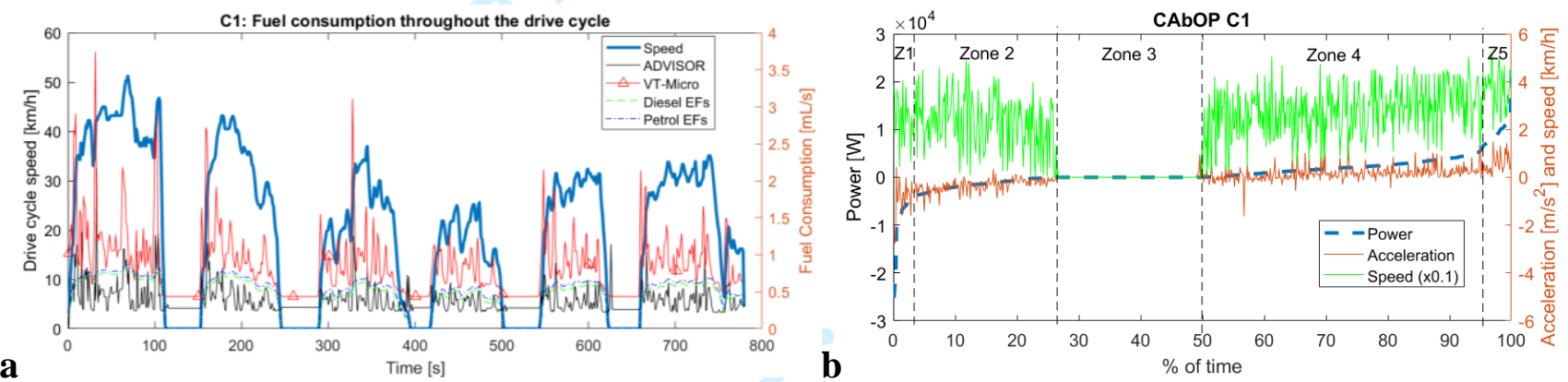

Figure 5. - (a) Second by second fuel consumption in C1, (b) Instant accelerations and Speeds in C1 CAbOP.

The graph in Figure 5a, leads to a visualization and analysis in the temporal domain and is a conventional way to express the results. However, we propose a Cycle Analysis by Ordered Power (CAbOP), as presented in Figure 5b, which expresses results in the power domain, providing an opportunity to obtain a different perspective of the results and visualize trends and phenomena that would remain unnoticed with the temporal domain approach.

\subsection{Reordered Data by Power Domain}

As an alternative method to analyze and compare the obtained results, all datasets are ordered in ascending order of required power. In case of a tie, first by ascending acceleration and finally by elapsed time. Then, the following figures show the instant values of Required Vehicle Power combined with the variable studied. The methodology presented can be called Cycle Analysis by Ordered Power (CAbOP). In order to facilitate comprehension of the analysis, a simplistic and intuitive 5-zone model has been created, as shown in Figure 2.

In continuation, the different simulation models used are compared using the CAbOP methodology in the $\mathrm{C} 1$ cycle. First, the characteristics of the cycle are represented in Figure 5b. The acceleration is negative in zones 1 and 2, zero in 3 and mostly positive and increasingly higher in zones 4 and 5. By contrast, the speed is, on average, constant in most of the zones, with the exception of the Idle zone, where it is obviously zero, and in the transitions to the Idle zone, which describe the instants immediately after and before reaching/leaving the Idle zone. 
Figure 6 shows a CAbOP comparison of the instant fuel consumption throughout the $\mathrm{C} 1 \mathrm{Cycle}$ obtained with each model. As VT-Micro represents a Petrol vehicle, the average consumption is found to be the highest, even when compared to the respective EFs for petrol vehicles, as shown in Figure 4a. Moreover, VT-Micro also presents the highest instant consumption in the CAbOP, clearly following the power trace in zones 4 and 5.

The EFs, which are exclusively dependent on speed, present similar consumption values throughout the 4 non-Idle zones. The Petrol vehicle registers higher consumption during the cycle than the Diesel. Due to the limitation of the model, the fuel consumption - as well as the rest of emissions presented - is set to 0 in Idle zone.

The Advisor results present low consumptions in zones 1 and 2, stable but greater-than-zero consumption in Idle zone and increasing consumption in zones 4 and 5, just as the acceleration does. Advisor also has subtle and stepwise variations of emissions in the Idle zone, due to the transition from cold to hot and simulation issues when stopping the vehicle.

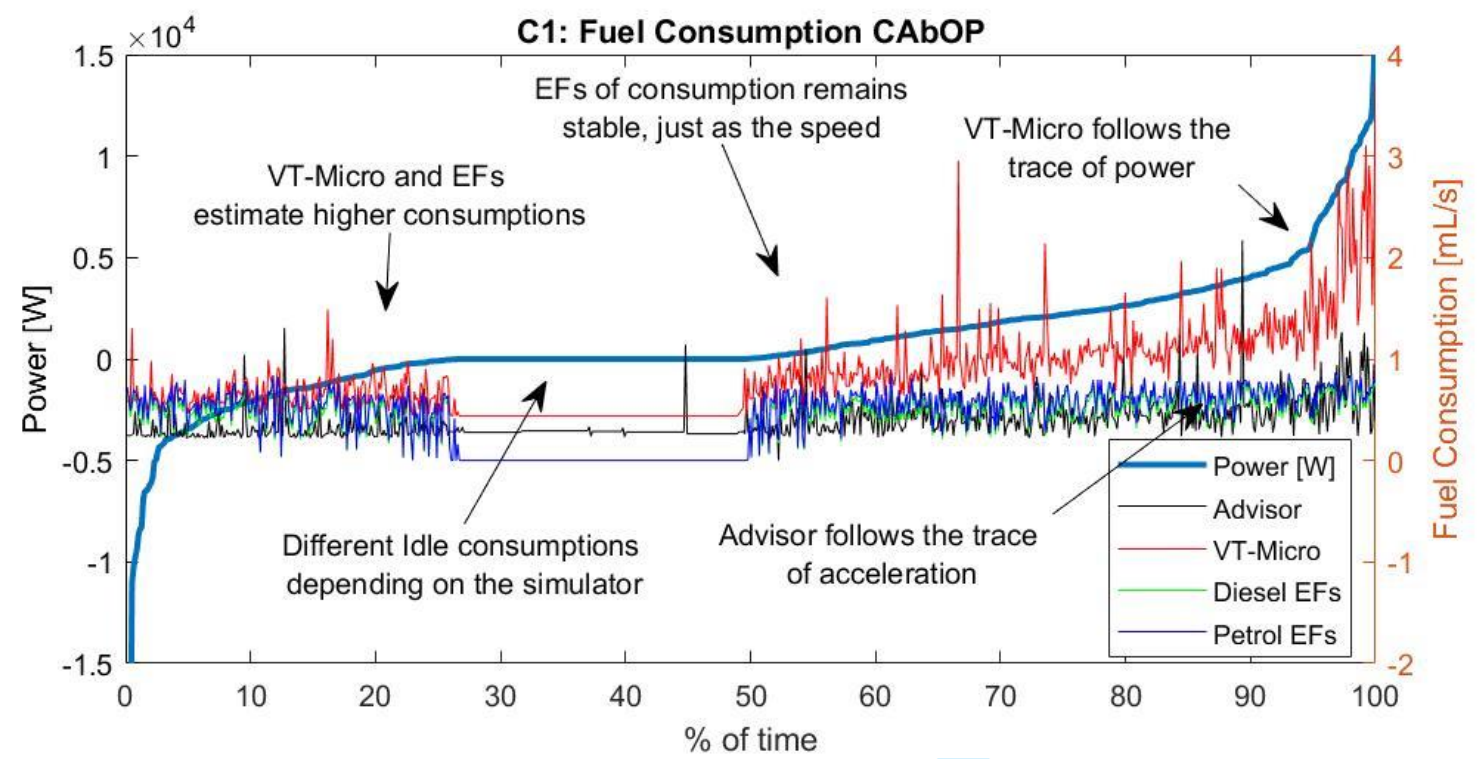

Figure 6. - Fuel consumption in each simulation comparison using CAbOP.

As the elapsed time is the last tie-breaker criteria, the steps shown represent each stop in the cycle. The results of NOx emissions are plotted in Figure 7. Both Diesel and Petrol EFs estimate constant emissions during the cycle, except in the Idle zone where they are zero; however, Diesel emissions are on average considerably higher than Petrol emissions. Advisor emissions closely follow the Power trace in zones 4 and 5 with a certain offset. At the beginning and ending of zone 3, two emission peaks appear, which are produced when engaging and disengaging the clutch, forcing the ICE to work at a low efficiency rate. This phenomenon will be referred as the "clutch effect". 


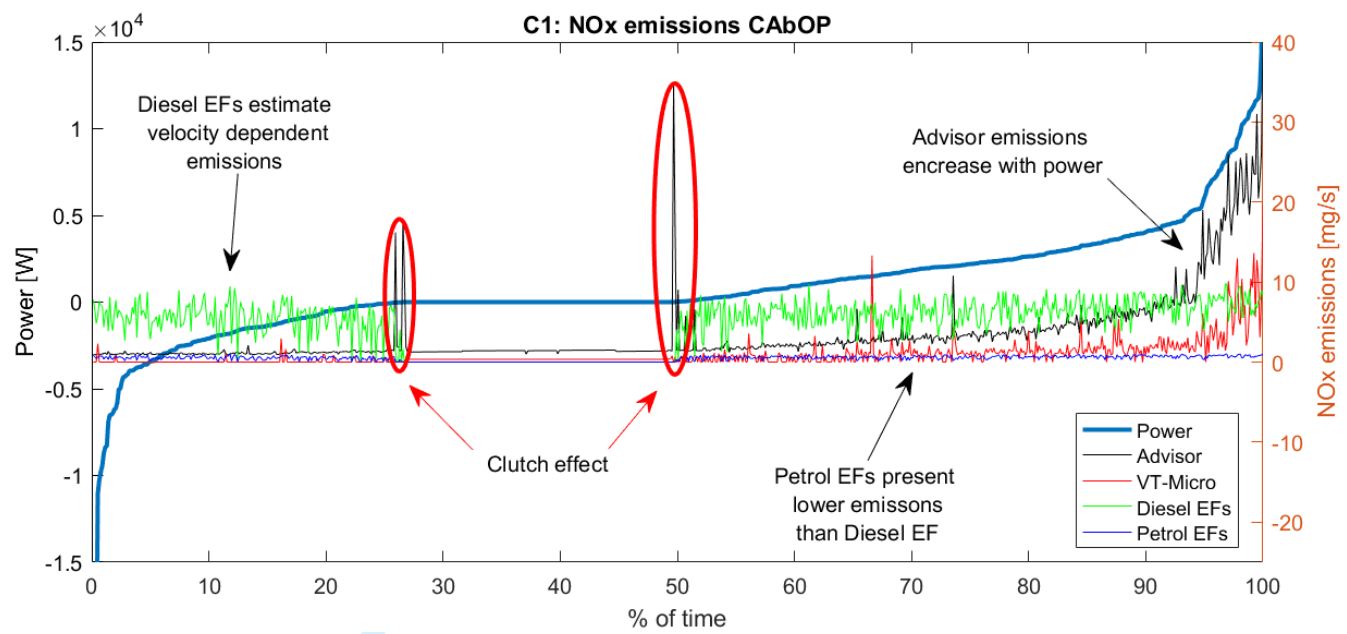

Figure 7.- NOx emissions in each simulation comparison using CAbOP.

Finally, VT-Micro NOx emission results are clearly lower than those representing diesel engines and follow the trace of acceleration in zone 4 and 5.

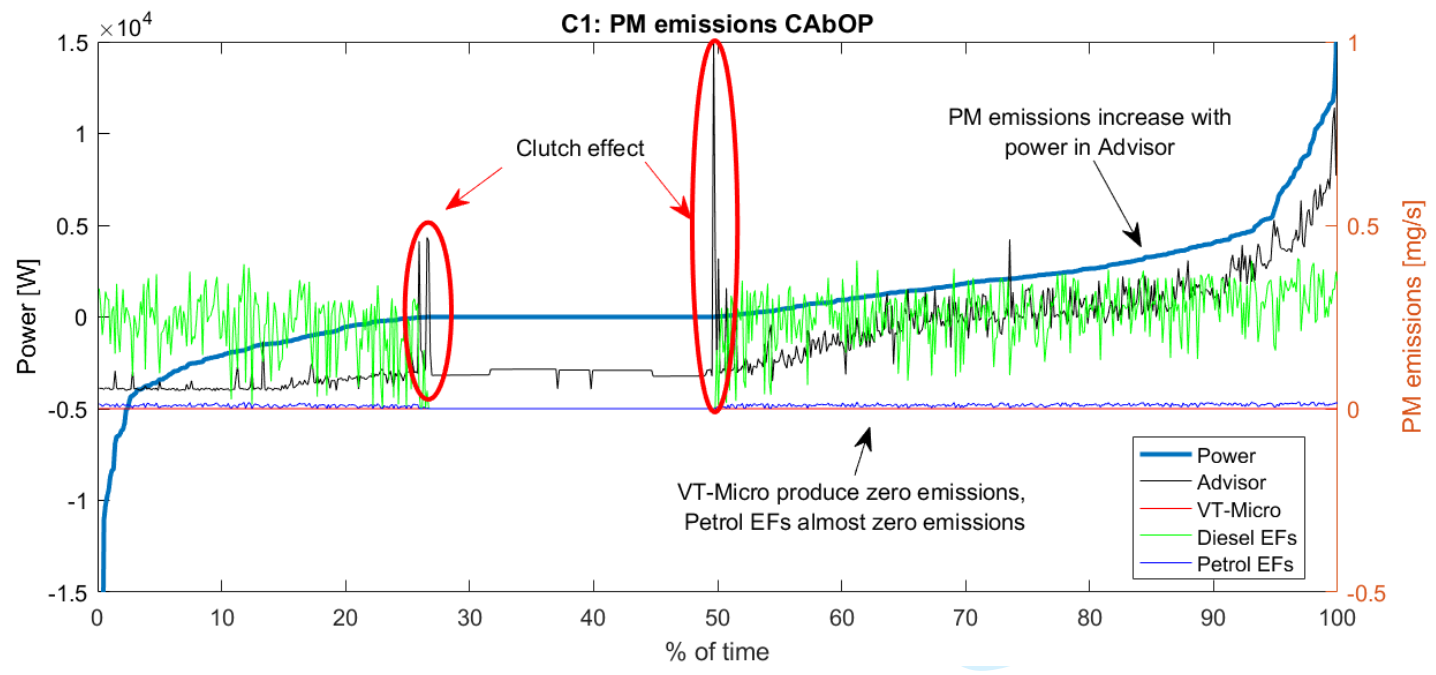

Figure 8. - PM emissions in each simulation comparison using CAbOP.

Figure 8 shows the PM emissions. The PM EFs for Petrol vehicles produce almost zero emissions and VT-Micro produce none. The PM EFs for Diesel are constant throughout the power domain and the noisy signal is caused by the EFs' dependency on speed. The Advisor vehicle produces low but progressively increasing emissions in zones 1, 2, and 3. Finally the emissions follow the trace of power in zones 4 and 5. The figure also presents peaks due to the clutch effect. 


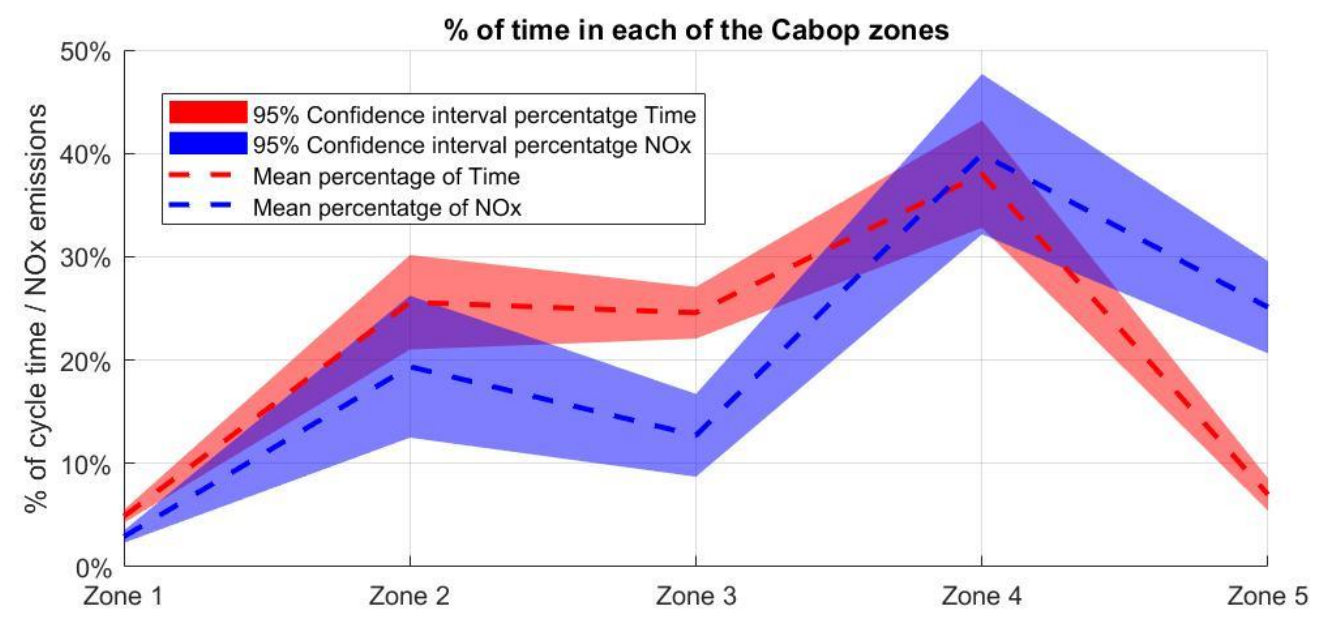

\section{Figure 9. - Percentage of the relative time spent in each of the driving zones compared to the relative emissions of NOx.}

Figure 9 shows the statistical analysis of the results for the 16 cycles analyzed. The percentage of time in which the vehicle is operating at each of the five zones is compared to the percentage of NOx emissions in those same zones. The most notable differences are found in Zones 3 and 5, where the two magnitudes are clearly distanced. In Zone 3, where the vehicle is not moving at all (but assuming that the engine is switched on) the relative emissions are below the relative elapsed time, while the opposite occurs in Zone 5 , where the vehicle performs the strongest accelerations.

\section{DISCUSSION}

As seen in the results section, the EFs methodology has valuable aggregated results and the differences between the two EFs approaches - the proposed second-by-second methodology and the standard average speed calculation - are low. However, the CAbOP and the second-by-second analysis in Figure 5b show how the EFs curve has a notably different shape compared to the Advisor and VT-Micro curves and is clearly unable to predict on a micro scale. Moreover, the second-by-second approach is unable to predict emissions when vehicle speed is between $0-5 \mathrm{~km} / \mathrm{h}$, due to the limitations of the model, leading to an extra source of error. This error, in contrast, has no effect on the constant speed approach, as average speeds lower than $5 \mathrm{~km} / \mathrm{h}$ are not common in real drive cycles.

The CAbOP performed in $\mathrm{C} 1$ has also provided some valuable information on how the fuel consumption and PM and NOx emissions evolve in the multiple situations found in a real drive cycle. In Figure 6 the Fuel Consumption CAbOP has shown how both VT-Micro and Advisor results are low in zone 1 and 2, increasing in zones 4 and 5. The Advisor curves follow the acceleration and the VT-Micro follows the Power. In zone 3, each simulator and engine show a different idle consumption.

The CAbOP Nox emissions have shown the different thresholds between Diesel and Petrol vehicles, with Petrol vehicles having considerably lower emissions. Still, the analysis has shown similar results in fuel consumption, evidencing that the emissions are related to the power. More precisely, in Zone 5, despite representing only around $6 \%$ of the total driving cycle time, the Advisor simulations produce on average $27.2 \%$ of the NOx emissions, and VT-Micro $34 \%$. 
This is the most likely reason for the manifest differences between emissions in real drive conditions regarding the WLTC.

The PM emissions also have similar behavior to the NOx emissions. In this case, however, the difference between Diesel and Petrol passenger vehicles is higher, to the point that VT-Micro estimates the particle emissions as zero. By contrast, in zone 5 the PM emissions are not as concentrated as the NOx emissions. In this case $\mathrm{z} 5$ accounts for $14.2 \%$ of the total emission, which is still high, but far from the ratio found with NOx. Moreover, PM emissions are overly attached to the power and follow its trace very clearly. Two remarkable features in every CAbOP figure are the anomalies in the Idle consumption and the "Clutch effect", both found in the Advisor results. To explain their origin, it is necessary to introduce the idea of emissions maps.

To calculate the fuel consumption, Advisor evaluates the working point of the engine for each instant of time and refers to the emissions maps to get the instant emission value. In the emission maps used in Advisor, the low power engine working points (low torque and low engine speed) produce low emissions, while the opposite happens in high power engine working points.

Therefore, the "clutch effect" comes from similar powers achieved in different working points. As the clutch makes the engine work at an unusual rate for a fraction of time, it produces a peak in emissions. On the other hand, the emissions anomalies found in Figures 7 and 8 are an example of a block diagram model malfunction. In this case the model fails to disengage the clutch during Idle, requiring high torque from the engine block, which then produces high emissions. In both cases, the results are insufficient to determine whether those are artificial effects of data discretization or not. However, the use of CAbOP is found to be effective in identifying them.

Regarding the effect of road grade, only considered in the Advisor simulations, the results differ depending on the figure. Fuel Consumption is found to be between $15 \%$ and $21 \%$ higher in the cycle with a road grade of $2 \%$. Regarding NOx emissions, Advisor responds to the road grade, emitting between $45 \%$ and $51 \%$ more than in flat cycles WLTC and C1 respectively. Finally, the PM emissions have been found to emit between $24 \%$ and $30 \%$ in the uphill cycle.

The VT-Micro simulator, which only considers Petrol vehicles, has been found to differ greatly from the correspondent EMEP/EEA EFs. Differences in NOx and CO estimations are $43 \%$ and $31 \%$ lower respectively, while Fuel consumption has been calculated as over $40 \%$ higher in the VT-Micro estimations. These differences are probably due to the fact that the simulated vehicles are larger than expected and clearly suggest that the VT-Micro is not appropriate for small vehicle simulation. Despite the fact that the road grade is not considered, the differences between the 3 studied cycles range from $4 \%$ to $9 \%$.

Regarding the studied cycles, there is not any major anomaly affecting the WLTC (homologation cycle) when it comes to the aggregated results of fuel consumption and emissions, compared with the real drive cycles. Finally, in Figure 9 the relative emissions of NOx of the 16 studied cycles are compared with the corresponding relative time. The results, as might have been expected, show that most of the emissions are produced when the vehicle is accelerating and sustaining its speed, although on average it does not account for even $50 \%$ of the time. As this is something well-known, the potential of CAbOP is that it can easily quantify this fact and be used to compare sets of cycles to find relevant differences or similarities.

\section{CONCLusion}

Several real drive cycles have been carried out in urban conditions, and two of them, representative of the majority, have been used to perform a comparative analysis of different fuel consumption and tailpipe emission estimation models for a small car. Three different emission models have been used: two micro 
models such as Advisor and VT-Micro and an adaptation of a statistical macro model, the EMEP/EEA EFs. A new tool for the analysis of results, called CAbOP, has been introduced. The conducted research had led to the following conclusions:

$>$ The use of micro simulations demonstrates the importance of using real drive cycles in order to obtain a precise second-by-second evaluation of fuel consumption and emissions. A simple and economical methodology has been presented for that purpose. A complete drive cycle data set must include road grade, as its influence is not negligible in urban conditions.

$>$ The EMEP/EEA EFs have been found to be good indicators for Diesel engines, although they are not adequate for micro simulations, as stated in the user's guide. The Advisor estimates have been found to be very sensitive to the engine's emissions map and vehicle configuration. This gives an idea of the complexity of emissions at a micro level, which makes it difficult to create regulations. If manufacturers could provide complete emission maps, it might become easier for administrations to provide clear and effective regulations and proposals.

$>$ VT-Micro has been found to be a balanced tool; however, its lack of actualized data, selfcustomization and road grade consideration, together with the absence of Diesel engine data, makes it an insufficient tool for a complete drive cycle study in European countries.

$>$ The CAbOP helps to compare different driving cycles and describes how the different pollutant emissions are produced. The analysis shows that NOx and PM emissions increase with power, as most of the cumulative emissions are linked to high power driving zones. More research using experimental data is still needed in order to apply the analysis tool to a more representative sample of driving patterns.

$>$ The CAbOP can potentially be used to create a representative cycle out of a greater experimental data collection, to find the average weight of each of the zones and assess the emissions produced by vehicles driving in a specific urban region or city. However, the present paper can only present the tool, and more research is still needed to exploit the full potential of CAbOP.

In conclusion, the present paper demonstrates the need for a new open source micro-scale fuel consumption and tailpipe emissions simulation model. It should be physically derived and be able, at least, to provide results for both Diesel and Petrol vehicles, grouped by mass or by engine size, provided by second-by-second drive cycle data.

\section{ACKNOWLEDGMENT}

The authors appreciate the support given by Juli Garcia Ramon and the contributions of Rubén Camúñez Llanos on creating the drive cycle tracking app.

\section{REFERENCES}

Ahn K, Rakha H, Trani A, Aerde M (2002). Estimating Vehicle Fuel Consumption and Emissions Based on Instantaneous Speed and Acceleration Levels. Journal of Transportation Engineering, 128 (2): 182-190 
Barth M, An F, Younglove T, Scora G, Levin, C, Ross M, Wenzel, T. (2000). The development of a comprehensive modal emissions model. NCHRP Web-only document, 122: 11-25

Ben-Chaim M, Shmerling E, Kuperman A (2013). Analytic modeling of vehicle fuel consumption. Energies, 6(1): 117-127

Bender W, Gruhl D, Morimoto N, Lu A (1996). Techniques for data hiding. IBM systems journal, 35(3.4): 313-336 Bromba M. U, Ziegler H (1981). Application hints for Savitzky-Golay digital smoothing filters. Analytical Chemistry, 53(11): 1583-1586

California Air Resources Board (2017). EMFAC2017 User's Guide V1.0.1. Sacramento: Mobile Source Analysis Branch. Air Quality Planning \& Science Division

Chen J, Jönsson P, Tamura M, Gu Z, Matsushita B, Eklundh L (2004). A simple method for reconstructing a highquality NDVI time-series data set based on the Savitzky-Golay filter. Remote sensing of Environment, 91(3-4): 332-344

Donateo T, Mattia G. (2017) Building a cycle for Real Driving Emissions. Energy Procedia (Elsevier), 126 (9): $891-$ 898

Duarte G O, Gonçalo A G, Tiago L F. A (2014). Methodology to Estimate Real-world Vehicle Fuel Use and Emissions based on Certification Cycle Data. Procedia - Social and Behavioral Sciences (Elsevier), 111 (2): $702-$ 710

Feng A, Matthew B, Joseph N, Marc R (1997). Development of a Comprehensive Modal Emissions Model: operating under hot-stabilized conditions. Transportation Research Record: Journal of the Transportation Research Board, 1587: 52-62

Hardin J W, Hardin J W, Hilbe J M, Hilbe J (2007). Generalized linear models and extensions. Stata Press. Haugh L (1976). Checking the independence of two covariance-stationary time series: a univariate crosscorrelation approach. Journal of the American Statistical Association, 71 (354): 378-385

Hentschel T, Fettweis G (2000). Sample rate conversion for software radio. IEEE Communications magazine, 38 (8): 142-150.

Horvatic D, Stanley H, Podobnik B (2011). Detrended cross-correlation analysis for non-stationary time series with periodic trends. EPL Europhysics Letters, 94 (1): 18007.

Kim K H, Kabir E, Kabir S (2015). A review on the human health impact of airborne particulate matter. Environment international, 74: 136-143.

Luo J, Ying K, Bai J (2005). Savitzky-Golay smoothing and differentation filter for even number data. Signal Processing, 85 (7): 1429-1434.

Malik A, Tauler R (2015). Exploring the interaction between 03 and NOx pollution patterns in the atmosphere of Barcelona, Spain using the MCR-ALS method. Science of the total Environment, 517: 151-161

Markel T, Brooker A, Hendricks T, Johnson V, Kelly K, Kramer B, Wipke K (2002). ADVISOR: a systems analysis tool for advanced vehicle modeling. Journal of power sources, 110(2): 255-266 
Ntziachistros L, Samaras Z (2017). EMEP/EEA emission inventory guidebook 2017 - exhaust emissions from road transport, passenger cars, light commercial trucks, heavy duty vehicles including buses and motor cycles. Copenhague. EMEP/European Environment Agency

Ntziachristos L. (2009). COPERT: A European Road Transport Emission Inventory Model. Information Technologies in Environmental Engineering. Springer Berlin Heidelberg. 491-504

Perez L, Medina-Ramón M, Kunzli N, Alastuey A, Pey J, Pérez N, Sunyer J. (2009). Size fractionate particulate matter, vehicle traffic, and case-specific daily mortality in Barcelona, Spain. Environmental science \& technology, 43(13): 4707-4714

Rakha H, Ahn K, Trani A (2003). Comparison of MOBILE5a, MOBILE6, VT-MICRO, and CMEM models for estimating hot-stabilized light-duty gasoline vehicle emissions. Canadian Journal of Civil Engineering 30 (6): 1010-1021

Rakha H, Ahn K, Trani A (2004). Development of VT-Micro model for estimating hot stabilized light duty vehicle and truck emissions. Transportation Research Part D: Transport and Environment, 9 (1): 49-74.

Rakha H, Ahn K, Moran K, Saerens B, Van den Bulck E. Virginia Tech Comprehensive Power-Based Fuel Consumption Model: Model development and testing. Transportation Research Part D: Transport and Environment (Pergamon), 16 (7): 492-503

Savitzky A, Golay M (1964). Smoothing and Differentiation of Data by Simplified Least Squares Procedures. Analytical Chemistry (American Chemical Society), 36 (8): 1627-1639.

Scora G, Barth M (2006). Comprehensive Modal Emissions Model (CMEM), version 3.01 User's Guide. University of California, Riverside: Center for Environmental Research and Technology.

Sigmon K, Davis T (2004). MATLAB primer. Chapman and Hall/CRC.

Silva C M, Farias T L, Christopher-Frey H, Nagui M R (2006). Evaluation of numerical models for simulation of real-world hot-stabilized fuel consumption and emissions of gasoline light-duty vehicles. Transportation Research Part D: Transport and Environment (Pergamon), 11 (5): 377-385

Tutuianu M, Bonnel P, Ciuffo B, Haniu T, Ichikawa N, Marotta A, Steven H (2015). Development of the Worldwide harmonized Light duty Test Cycle (WLTC) and a possible pathway for its introduction in the European legislation. Transportation research part D: transport and environment, 40: 61-75.

United States Enviromental Protection Agency (2015). MOVES2014a User Guide. https://nepis.epa.gov/Exe/ZyPDF.cgi?Dockey=P100NNCY.pdf (accessed September 3, 2018).

United States Environmental Protection Agency (2002). User's Guide to MOBILE6.1 and MOBILE6.2: Mobile source emission factor model. https://nepis.epa.gov/Exe/ZyPDF.cgi/P1001DSD.PDF?Dockey=P1001DSD.PDF (accessed September 3, 2018).

Wipke K B, Cuddy M R, Burch S D (1999). ADVISOR 2.1: A user-friendly advanced powertrain simulation using a combined backward/forward approach. IEEE transactions on vehicular technology, 48(6): 1751-1761 


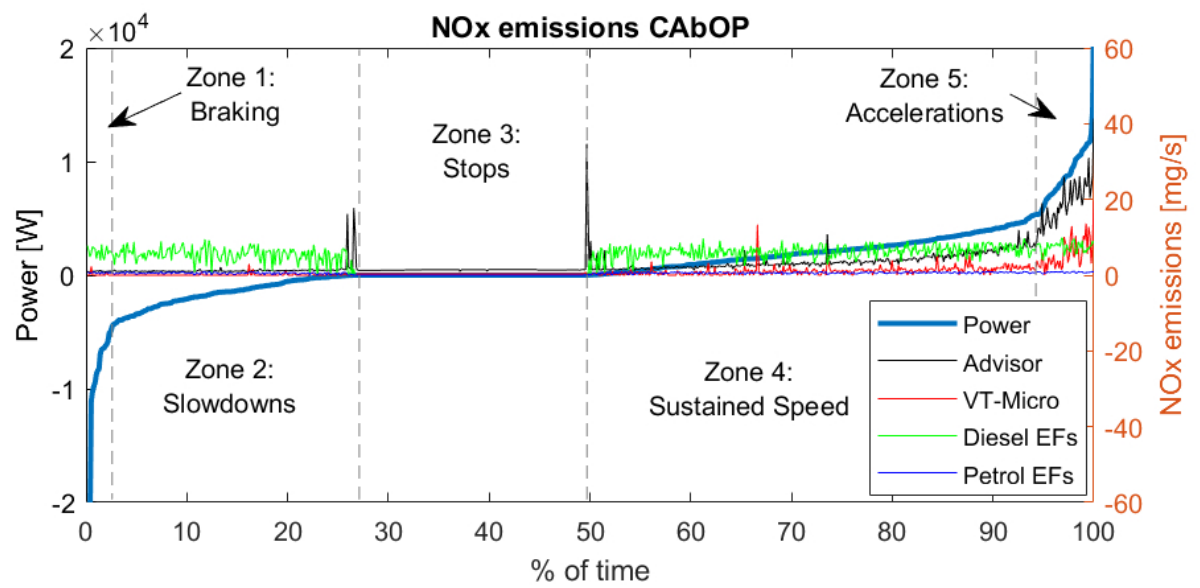

